\title{
An irrigation model for use in river systems modelling
}

\author{
J.D. Hughes $^{\text {a }}$, M. Mainuddin ${ }^{\text {a }}$, J. Lerat ${ }^{\text {a }}$, D. Dutta ${ }^{\text {a }}$, S.S.H. Kim ${ }^{\text {a }}$ \\ ${ }^{\text {a } C S I R O ~ L a n d ~ a n d ~ W a t e r, ~ B l a c k ~ M o u n t a i n, ~ A C T, ~ A u s t r a l i a ~}$ \\ Email: Justin.Hughes@csiro.au
}

\begin{abstract}
Irrigation diversion is a key component of the water balance in regulated river systems. However, diversion data are scarce and often require the use of a model to estimate the amount of water diverted. Such models have no need to simulate crop yields and therefore can be simpler in some regards. However irrigation diversion must be able to simulate whole of district behaviour in terms of irrigation diversions, volumes, and soil water balance. Additionally, the model must capture the district/area response to changing water availability. To be useful in the river modelling context the model must also produce daily estimates of diversion and consumptive water use. Considering all these, we have developed an irrigation diversion model which has been presented here.
\end{abstract}

The model is based upon an FAO crop model approach utilising crop factor curves for various crops. Additionally, soil moisture accounting is used to schedule diversions to irrigation from river allocations, or if available, groundwater licences and on farm storage. Total area planted is determined at four annual decision dates based upon a function varying with available resources. To account for variation in scheduling approaches and soil water holding capacity, a crop irrigation function dependent upon soil moisture and a Gaussian distribution is utilised. The irrigation diversion model has been trialled in association with the Australian Water Resources Assessment project. The model features five calibrated parameters and has been calibrated against observed monthly and daily diversions in irrigation districts in the Murray, Goulburn, Murrumbidgee, Macquarie and Namoi valleys. Good agreement with observed monthly diversion is achieved with Nash Sutcliffe Efficiencies generally within the $0.4-0.8$ range, and bias less than $10 \%$. The model has significant potential for estimation of river diversions even where there is limited available data with which to calibrate.

Keywords: Diversion, river system modelling, calibration 


\section{INTRODUCTION}

In the Murray-Darling Basin (MDB), average annual runoff is 24,300 GL with 11,400 GL of long term average diversions to irrigated agriculture. This in turn produces around $14 \%$ of Australias total gross value of agricultural production (ABS, 2009). Given the importance of irrigation and its impact on water resources, it is valuable to have methods to estimate any future diversions. However, data with which to assist in parameterisation of estimation algorithms is difficult to source. Alternatively, many models require a high level of user expertise and knowledge of specific irrigation areas and practices.

Presently, models are in development to support the river component of the Australian Water Resources Assessment system (AWRA-R Dijk et al. (2012)) developed jointly by CSIRO and the Bureau of Meteorology as part of the Water Information Research and Development Alliance (WIRADA). The model presented here is a proto-type irrigation model for use within AWRA-R. The FAO crop factor (Allen et al., 1998) method has been used extensively to estimate irrigation demand in many widely used models such as CROPWAT (Smith, 1992), AquaCrop (Steduto et al., 2009) for irrigation planning and management. Mainuddin et al. (2007) used this approach to estimate reach-wise diversion requirements in the Murray-Darling Basin. The irrigation demand model used in AWRA-R utilises this method, to calculate crop demand based on crop types planted.

While models already exist which can be used to estimate diversion, e.g. IQQM crop model (Simons et al., 1996), these cannot be calibrated and require a high degree of operator experience. Given this context, the AWRA-R irrigation model has been designed to estimate diversions with limited data, while still attempting to represent some important processes.

\section{METHODS}

\subsection{Crop demand}

Crop demand (mm/day) is calculated as follows;

$$
E T_{c, i}=K c_{i} * E T_{o, i}
$$

where $E T_{c, i}$ is crop demand (mm) for any each crop $c$, on day $i . K c_{i}$ is the crop factor for any crop $c$ on day $i$ and $E T_{o, i}$ is the Penman FAO56 reference crop ET (user supplied time-series).

The crop factor is determined by locally modified crop coefficient curves that specify the crop factor throughout the life cycle of the crop, starting with the sowing date, through crop development, senescence and harvesting. The AWRA-R irrigation model utilises a crop table in model calibration that lists crop factors and sowing dates for many common crops.

\subsection{Crop area}

Any estimation of irrigation diversion or groundwater extraction at a reach or district scale will obviously require consideration of the areas of all crops and their requirements. To reduce the complexity of calculations involving multiple crops, the AWRA-R irrigation model utilises a weighted average annual $K c_{i}$ curve. This requires a ratio of crops that will be planted in all years. For example, an irrigation district may be assumed to plant $70 \%$ winter pasture, $20 \%$ rice, and $10 \%$ wheat by area. The weighted $K c$ was calculated as follows;

$$
K w_{i}=\sum_{c=1}^{n} K c_{i} * \operatorname{Pro}_{c, i}
$$

where $K w_{i}$ is the weighted crop factor on day $i, K c_{i}$ is the crop factor for crop $c$ on day $i$ and $\operatorname{Pro}_{c, i}$ is the proportion of area sown to crop $c$ on day $i$ (all dimensionless).

Irrigated annual crops are generally regarded as "summer" or "winter" crops, being sown in spring and autumn respectively. The allocation of water must take into account this when planting decisions are made, i.e., some of the water available in spring must be reserved for winter crops if they are part of the portfolio of crops assumed to be grown for the area. These reservations are encapsulated in the calculation of $K w_{i}$.

Maximum crop area sown (summer and winter) is calculated as follows;

$$
\operatorname{areaMax}=\operatorname{volMax} /\left(\sum_{j=1}^{366} \overline{E T}_{o, j} * K w_{j} * \text { efficiency }\right)
$$


where areaMax is the maximum area that can be planted in any year $\left(\mathrm{km}^{2}\right)$, volMax is the maximum volume of water available, or likely to be available in any single year (ML), $E T_{o, j}$ is the average $E T_{o}$ with respect to julian day $j(\mathrm{~mm}), K w_{j}$ is the weighted crop factor on julian day $j$ (dimensionless), and efficiency is the irrigation efficiency factor (dimensionless).

This irrigation model considers three potential sources of irrigation water; surface water diversions via allocation, groundwater via a licence and on-farm storage that considers flood plain harvest and re-use. Water resources and climatic input vary from year to year and within years. The model must, therefore, incorporate algorithms that will adjust area sown to crops dependent upon available resources. Such a function must incorporate the collective behaviour of an irrigation district in response to changing surface water allocations and/or availability of groundwater and on-farm storage of water. In this regard, the model updates area planted at one of 5 decision dates, designed to coincide with crop sowing periods in spring and autumn. Area planted is calculated as follows;

$$
\operatorname{area} C_{d}=\operatorname{areaMax} * \frac{\operatorname{vol} A_{d} / \operatorname{volMax} * \alpha}{\operatorname{vol} A_{d} / \operatorname{volMax}+\beta}
$$

where $\operatorname{area} C_{d}\left(\mathrm{~km}^{2}\right)$ is the area that is planted on decision date $d, \alpha$ and $\beta$ are parameters (dimensionless) that are calibrated for each reach against observed diversion data. vol $A_{d}(\mathrm{ML})$ is the total volume of water resources available at the decision date, where;

$$
\operatorname{vol}_{d}=\text { allocation }_{d} * \operatorname{licVol}+\operatorname{volOF} S_{d}+\operatorname{vol} G W_{d}
$$

where allocation $_{d}$ is a user supplied time series input, licVol is surface water entitlement, volOFS is current on-farm storage, and volGW is remaining groundwater entitlement.

\subsection{Irrigation demand and requirement}

Crop irrigation requirement will differ from crop demand due to the effects of soil water storage and rainfall. These effects are particularly important at a daily time step. For example, after significant rain, crop irrigation requirement will be reduced for a number of days due to higher soil moisture.

A simple storage of a given capacity could be utilised to determine if irrigation is required, i.e., when soil water storage falls to a minimum level, irrigation is triggered. This concept is relevant for a single irrigated field but is not applicable to a whole district, since a district comprises of many differing soil types, irrigation structures and management philosophies. The resulting irrigation requirement for a district becomes distributed in time. To account for the effect of soil moisture storage and variation in irrigation practice across a district, a soil water storage based function was used to trigger irrigation. As soil water becomes more depleted, increasingly more irrigation diversion/consumption is triggered, until a maximum depletion where irrigation requirement is also maximised. The function used is based upon the normal distribution and user defined maximum storage capacity.

$$
\text { irri }_{i}=\left\{\begin{aligned}
\left(\left(\frac{\gamma}{\sigma \sqrt{2 \pi}}\right) e^{-\frac{\left(S S_{i}-\mu\right)^{2}}{2 \sigma^{2}}}\right) * \text { areaC }_{i} * \text { areaAct }_{i} * \text { eff } & \text { if soilCap } \geq S S_{i}>0 \\
\frac{\gamma}{\sigma \sqrt{2 \pi}} * \text { area }_{i} * \text { areaAct }_{i} * \text { eff } & \text { if } S S_{i} \leq 0 \\
0 & \text { if } S S_{i}>\text { soilCap }
\end{aligned}\right.
$$

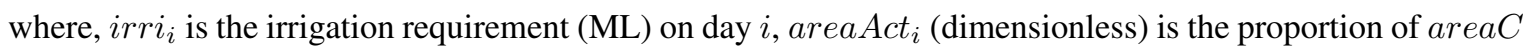
actively growing crops on day $i$, eff is the irrigation efficiency (dimensionless, of range 1-2), soilCap is the user defined soil water capacity (mm), $\gamma, \sigma$ and $\mu$ are constants of the normal distribution function, $S S_{i}$ is the depth of soil water available on day $i$. Soil water available can become negative, in which case a maximum irrigation requirement is utilised.

Soil water from the previous time step is updated with the depth of irrigation, rainfall and crop demand. Any excess water i.e., $S S_{i}$ greater than soilCap, is considered to be runoff;

$$
S S_{i}=S S_{i-1}-\left(\frac{K w_{i} * E_{i}}{\text { areaAct }_{i}}\right)+\left(\frac{\text { irri }_{i-1}}{\text { areaC }_{i} * \text { areaAct }_{i} * e f f}\right)+P_{i}
$$


J.D. Hughes and M. Mainuddin, An irrigation diversion model...

and

$$
\operatorname{runoff}_{i}=\max \left(0,\left(S S_{i}-\operatorname{soilCap}\right) * \operatorname{area}_{i} * \operatorname{areaAct}_{i}\right)
$$

where runof $f_{i}$ is the runoff (ML) from the area of actively growing crops and $P_{i}(\mathrm{~mm})$ is the user-supplied precipitation (from time-series input).

\subsection{Irrigation from different water sources}

The model algorithm can utilise three possible water sources (surface water allocation, groundwater and onfarm storage). The model will use water from each of these sources in proportion to their availability. Volumes in each source are updated at each time step and the proportion of irrigation satisfied by each source is updated at each decision date. Surface water allocation is adjusted according to a current water allocation, while groundwater is utilised from an annual licence volume that is replenished on 1 July each year. On-farm storage is emptied as for groundwater. The model has a mechanism for input into on-farm storage that mimics floodplain harvesting.

Diversion, for example is calculated as follows;

$$
\operatorname{div}_{i}=\operatorname{irri}_{i} *\left(\frac{\text { allocation }_{d} * \text { licVol }}{\text { allocation }_{d} *{\text { licVol }+\operatorname{vol} G W_{d}+\operatorname{volOF} S_{d}}_{1}}\right)
$$

where $\operatorname{div}_{i}(\mathrm{ML})$ is the surface water diversion on day $i$, while $s u r f_{d}, g w_{d}$ and $o f s_{d}$ are surface water entitlement, groundwater, and on-farm storage available on the most recent decision day, $d$.

\subsection{On-farm storage}

On farm storage for any reach is limited by a user-defined upper bound. Water is supplied to this storage when river flow exceeds a threshold value. Furthermore, rate of input to the storage is restricted by a pre-defined pump capacity for the reach;

$$
\operatorname{volOFSin}_{i}=\min \left(\min \left(\operatorname{pump}, \max \left(0, Q_{i}-\text { OFSthresh }\right)\right), \operatorname{volOFSmax}-\operatorname{volOF}_{i-1}\right)
$$

where $Q_{i}$ (ML/day) is the rate of river flow on day $i$, pump(ML/day) is the maximum pump capacity for the district/reach and OFSthresh (ML/day) is the threshold river flow above which water is diverted from the river into storage. Water is removed from storage by irrigation and evaporation. To account for evaporation and precipitation, an on-farm storage surface area/volume relationship is required.

\subsection{Parameter estimation}

The model requires some user knowledge of the irrigation area in question. The user must input the types and proportions of crops grown in the area $\left(\mathrm{Pro}_{c}\right.$, Equation 2) the soil water capacity ( soilCap, Equation 6), and the maximum volumes available in each of three water sources (surface water licVol, onfarm storage volOFS and groundwater entitlement volGW - see Equation 5). The model is calibrated against observed water use data. To date, all calibration has been against observed diversion. The five calibrated parameters are;

1. $\alpha$ from Equation 4

2. $\beta$ from Equation 4

3. OFSthresh from Equation 10

4. pump from Equation 10

5. smooth - a smoothing parameter for the $K w$ curve

The parameter smooth determines what level of smoothing is applied to the $K w$ curve according to the following equation; 
J.D. Hughes and M. Mainuddin, An irrigation diversion model...

$$
K \text { smoot }_{i}=\sum_{i-\text { smooth } / 2}^{i+s m o o t h / 2} K w_{i} /(\text { smooth }+1)
$$

where, $i$ is day and smooth is the number of days across which averaging occurs. The higher the number, the more smoothing is applied. This was found to be necessary in some areas since the observed time series of diversion exhibit higher diversion during spring and autumn than time series modelled without any smoothing of $K_{w}$. This was thought to be related to non-demand based diversion, and was evident in southern NSW and Victoria. In these areas, practices such as "watering-up" of winter pasture, and filling of rice bays before aerial sowing, mean that, at least some of the observed diversion, is not related to crop demand. Where this occurred $K$ smooth replaced $K w$ in water balance calculations (Equation 7).

The objective function used to determine goodness of fit between observed and simulated diversion, combined overall bias and error between simulated and observed diversion:

$$
O F=\sum_{i=1}^{n}\left(\sqrt{d \hat{i} v_{i}}-\sqrt{d i v_{i}}\right)^{2} *\left(\left|\frac{\sum d \hat{i} v_{i}-\sum d i v_{i}}{\sum d i v_{i}}\right|+1\right)
$$

where $d \hat{i} v$ is the simulated diversion time series and $d i v$ is the observed diversion time series.

\subsection{Data used for testing}

Diversion time series used in calibration and evaluation come from three sources. In NSW, the MDB Sustainable Yields (MDBSY) project required diversion estimates across the NSW portion of the MDB for water accounting, and projection of climate change effects on basin water resources. Due to the lack of observed data, these data have been used for calibration. For model testing in Victoria, monthly observed diversion data were obtained from Goulburn-Murray Water. Goulburn-Murray Water also provided historical allocation announcement data. In some locations, gauged off-take channel data were utilised.

Crop information encapsulated in the individual crop $K_{c}$ curves was adapted from those in Allen et al. (1998) using local expertise. Crop types and crop proportions for each area have been obtained via expert knowledge and literature for each region. Licence diversion volumes for each reach/district could sometimes be obtained via published literature. However, where this was not the case, and diversion data were available, the licence volume was assumed to be the maximum volume diverted (from observed diversion) in any one irrigation year.

\section{Results}

The irrigation model was calibrated in 17 different reaches/districts. In some instances these estimates consisted of aggregated diversion since two districts might divert water from a river within the same reach (e.g. Yarrawonga Weir). Where possible, observed data were used for model calibration. These varied in quality, length of record and estimation/measurement method. For example, some data were obtained directly from stream gauges on irrigation district off-take channels, while others came via irrigation district management staff, and the exact nature of these data is often unknown. In many regions, the only data available were previous estimations via models (IQQM/MDBSY). Table 1, below shows the district diversions estimated by the model and goodness of fit statistics.

In general, the model performed well particularly for those areas where calibration data consisted of measured diversion from off-take channels (Murray and Goulburn districts). In other areas, where models were calibrated against model estimates of diversion, it is unknown why goodness of fit was generally poorer. The model can be implemented to estimate internal model states, although there is very little data with which to evaluate these. Figure 1 shows an example of some of the model outputs. In this example crops mix by area consisted mainly of cotton $(90 \%)$ with some irrigated wheat $(10 \%)$. The model was calibrated against diversion data, while only annual estimates of groundwater usage were available, so daily groundwater use estimates remain un-evaluated. 
J.D. Hughes and M. Mainuddin, An irrigation diversion model...

Table 1. Goodness of fit statistics for diversion estimates by the irrigation model

\begin{tabular}{cccc}
\hline River & District/Reach & NSE & Bias (\%) \\
\hline Murrumbidgee & Gogelderie & 0.72 & 1.1 \\
Murrumbidgee & MIA main & 0.69 & 1.1 \\
Goulburn & Shepparton & 0.86 & -4.8 \\
Goulburn & Central Goulburn & 0.82 & -1.9 \\
Murray & Yarrawonga main & 0.79 & -1.2 \\
Murray & National channel & 0.47 & 0.1 \\
Murray & Wakool main & 0.5 & -0.7 \\
Macquarie & 421019 & 0.56 & -3.2 \\
Macquarie & 421001 & 0.69 & -1.9 \\
Macquarie & 421031 & 0.47 & -0.5 \\
Macquarie & 421004 & 0.39 & -0.7 \\
Macquarie & 421088 & 0.56 & -0.1 \\
Macquarie & 421022 & 0.57 & 0.5 \\
Bogan & 421069 & 0.55 & -3.4 \\
Macquarie & 421118 & 0.5 & -4.3 \\
Namoi & 419059 & 0.12 & -1.5 \\
Namoi & 419068 & 0.49 & -1.1 \\
\hline
\end{tabular}

\section{Conclusion}

The paper presented a simplified daily irrigation diversion model designed for use in river system modelling for water resources accounting and planning. The model shows potential for estimation of daily diversion given limited data and user experience. However, data availability are the main impediments to thorough evaluation of the model, especially groundwater and on-farm water storage components.

\section{ACKNOWLEDGEMENTS}

This work was funded by the WIRADA research alliance between the Bureau of Meteorology and the CSIRO. The climate and streamflow data were provided by the Bureau of Meteorology. Victorian diversion estimates were provided by Goulburn-Murray Water.

\section{REFERENCES}

ABS (2009). Experimental estimates of the gross value of irrigated agricultural production, 2000-01 to 200607. Technical Report 4610.0.55.008, Australian Bureau of Statistics, Canberra.

Allen, R. G., L. S. Pereira, D. Raes, and M. Smith (1998). Crop evapotranspiration - guidelines for computing crop water requirements. Technical Report FAO Irrigation and drainage paper 56, FAO - Food and Agriculture Organization of the United Nations.

Dijk, A. I. J. M. V., R. S. R. S. C. Stenson, A. Frost, J. L. L. Renzullo, D. Barratt, D. Bacon, C. Daamen, P. Fitch, J. P. Guerschman, B. Henderson, N. Herron, E. King, T. McVicar, L. Minty, Z. P. P. Smith, and N. Viney (2012). The australian water resources assessment system. Technical report, CSIRO: Water for a Healthy Country National Research Flagship.

Mainuddin, M., M. Kirby, and M. Qureshi (2007). Integrated hydrologic-economic modelling for analyzing water acquisition strategies in the murray river basin. Agricultural Water Management 93, 123 - 135.

Simons, M., G. Podger, and R. Cooke (1996). IQQM - a hydrologic modelling tool for water resource and salinity management. Environmental Software 11, 185-192.

Smith, M. (1992). Cropwat: A computer program for irrigation planning and management. FAO Irrigation and Drainage Paper 46, Food and Agriculture Organisation of the United Nations.

Steduto, P., T. C. Hsiao, D. Raes, and E. Fereres (2009). Aquacrop - the fao crop model to simulate yield response to water: I. concepts and underlying principles. Agronomy Journal 101, 426 - 437. 

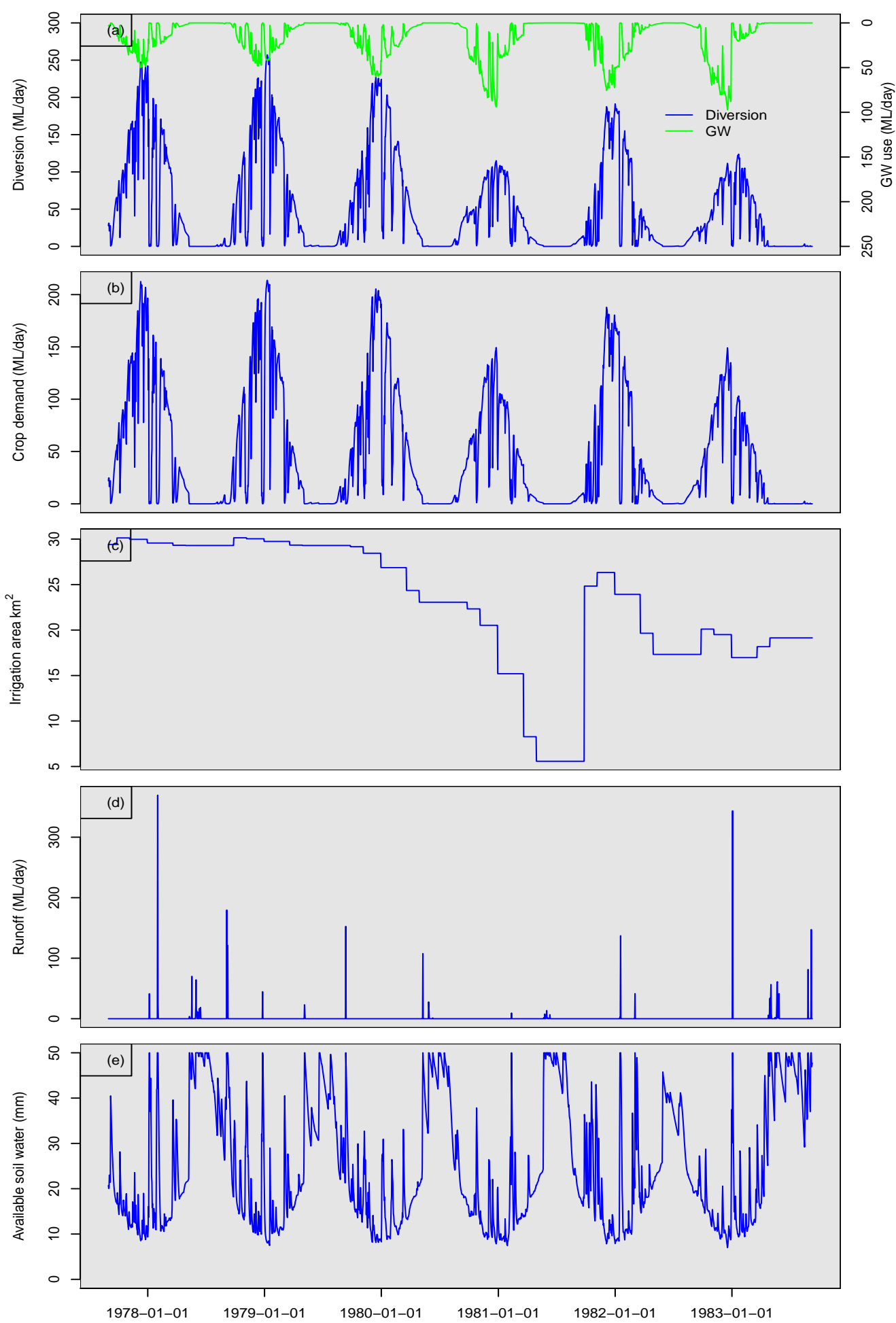

Figure 1. Sample output from the irrigation model for a district in the Namoi valley; (a) Diversion and groundwater use, (b) District irrigation demand, (c) Irrigated area, (d) Runoff from irrigated areas and (e) Available soil water for irrigated areas 